\title{
CAMINHOS QUE SE INTERCRUZAM ENTRE A EDUCAÇÃO DO CAMPO E A EDUCAÇÃO DE JOVENS E ADULTOS: MARCAS DA EDUCAÇÃO POPULAR
}

Liliane Borba Castro

Adenilson Souza Cunha Júnior ${ }^{2}$

RESUMO: Este artigo objetiva, através de uma revisão de literatura, realizar uma análise sobre a importância da educação no processo de desenvolvimento humano, levando em consideração o contexto da Educação Popular para a formação da Educação do Campo e da Educação de Jovens e Adultos (EJA). Nessa abordagem, a relação histórico-social entre campo, sujeitos e movimentos sociais foi apresentada tendo como enfoque a Educação do Campo, observando sua articulação com a Educação Popular num projeto de educação emancipatória. Na reflexão acerca da relação existente entre Educação Popular e Educação de Jovens e Adultos, a análise demandou o reconhecimento da EJA enquanto representação popular e também como modalidade de ensino, trazendo como referência sua identidade de luta frente à conquista de direitos. As discussões evidenciam que os interesses capitalistas interferem diretamente na sociabilidade humana, impondo um modo de existência e sobrevivência que muitas vezes desconfiguram a pessoalidade e as características peculiares a um determinado contexto social ou regional, configurando-se num processo de negação ou privação de direitos educacionais.

Palavras-chave: Educação do Campo; Educação Popular; Educação de Jovens e Adultos.

\section{PATHS THAT INTERFACE BETWEEN FIELD EDUCATION AND YOUTH AND ADULT EDUCATION: BRANDS OF POPULAR EDUCATION}

ABSTRACT: This article aims, through a literature review, to carry out an analysis on the importance of education in the human development process, taking into account the context of Popular Education for the formation of Rural Education and Youth and Adult Education (EJA). In this approach, the historical-social relationship between field, subjects and social movements was presented with a focus on Rural Education, observing its articulation with Popular Education in an emancipatory education project. In reflecting on the relationship between Popular Education and Youth and Adult Education, the analysis demanded the recognition of EJA as a popular representation and also as a teaching modality, bringing as a reference its identity in the struggle against the conquest of rights. The discussions show that capitalist interests directly interfere in human sociability, imposing a way of existence and survival that often disfigure personality and characteristics peculiar to a given social or regional context, configuring a process of denial or deprivation of educational rights.

Keywords: Rural Education; Popular Education; Youth and Adult Education.

\footnotetext{
${ }^{1}$ Mestre em Educação pelo Programa de Pós-Graduação em Educação da Universidade Estadual do Sudoeste da Bahia (UESB). Professora da Rede Estadual de Ensino da Bahia (SEC-BA). lilianneborba@hotmail.com

${ }^{2}$ Doutor em Educação. Professor Adjunto do Departamento de Ciências Humanas, Educação e Linguagem e do Programa de Pós-Graduação em Educação da Universidade Estadual do Sudoeste da Bahia (UESB). adenilsoncunha@uesb.edu.br
} 


\section{INTRODUÇÃO}

A educação está prevista na Constituição Federal de 1988 como um direito, portanto, precisa ser compreendida a partir do princípio da igualdade, tendo em vista o fato de ser um fundamento dos direitos sociais. Nesse sentido, a educação tem um papel importante de transformação da sociedade, mas antes disso, sua função social perpassa pelo contexto histórico e a partir dele vai delimitando novos caminhos e possibilitando a construção de sua realidade, pautada na humanização e libertação pelo conhecimento.

A história da educação no Brasil se apresenta através de um processo marcado por contradições, tendo em vista um jogo de interesses que sempre esteve por trás do objetivo maior, o qual consiste em possibilitar um ensino de qualidade para todas as pessoas. Devido ao fato de não haver uniformidade na oferta e no acesso, essa distinção levou as classes dominantes a uma situação de privilégio, e as camadas mais pobres da sociedade a uma condição de exclusão.

Nesse contexto estão inseridas a Educação do Campo e a Educação de Jovens e Adultos, caracterizando-se, a partir da Educação Popular, como representações de lutas e conquistas, considerando o cenário de omissão de direitos a que foram submetidas. De igual modo, a posição secundária e excludente a que também foram condicionadas, bem como o fato de se constituírem como expressão da Educação Popular, caracterizam-se como ponto de chegada da análise deste artigo, devido ao caráter de emancipação humana presente em suas dimensões educativas.

Tendo em vista a compreensão das discussões que envolvem a temática, a produção deste artigo centrou-se numa metodologia embasada em referenciais teóricos que retratam a Educação do Campo e a Educação de Jovens e Adultos, constituindo-se, portanto, num estudo bibliográfico. As reflexões aqui apresentadas encontram-se ancoradas nos estudos de Ribeiro (2010), Santos (2016) e Caldart (2004) para discutir a Educação do Campo; Brandão (1 985), Melo Neto (2011), Beisiegel (1982) e Vale (2001) que foram referenciados na reflexão acerca da Educação Popular; e quanto à Educação de Jovens e Adultos, levou-se em consideração o pensamento de autores como Oliveira (2007), Andrade (2012), Aguiar (2001), Cury (2005) e Rummert (2007), além de alguns marcos legais importantes para essa discussão, como a Lei de Diretrizes e Bases da Educação Nacional (1996) e Diretrizes Curriculares Nacionais para Educação de Jovens e Adultos (2000). 


\section{REFLEXÕES SOBRE A EDUCAÇÃO POPULAR}

A educação não se limita ao espaço escolar institucional, na verdade ela extrapola os espaços físicos das salas de aula, ultrapassando as barreiras geográficas e compondo a história dos sujeitos nos respectivos contextos. De acordo Brandão (1985) não é possível estabelecer uma definição, pois "não há uma forma única e nem um único modelo de educação; a escola não é o único lugar onde ela acontece e talvez nem seja a melhor; e o ensino escolar não é a sua única prática e o professor não é o seu único praticante". (BRANDÃO, 1985, p. 9)

Em seu percurso ao longo do tempo, a educação popular tem sua essência marcada por um contexto de exclusão social sofrido pelas classes populares, que também eram consideradas marginalizadas. Por outro lado, apesar de ser colocada à margem da sociedade (devido a uma valorização da educação voltada à elite), nota-se também que a dimensão popular constituiu-se de forma relevante no contexto político nacional, a partir da atuação dos movimentos populares em seus espaços de luta e enfrentamento, dinamizando o cenário histórico com as conquistas alcançadas.

É interessante observar que apesar de nascer fora do ambiente escolar, a educação popular ultrapassou seus limites externos e repercutiu para os muros internos das escolas e das instituições, tendo sua proposta aplicada como prática educativa em vários contextos institucionais, haja vista seu propósito de integrar os sujeitos na transformação e construção de sua própria realidade, assim como afirma Melo Neto (2011):

a educação popular é um movimento prático e teórico em educação, presente em processos de organização das classes trabalhadoras, sobretudo, que apresenta profunda crítica à educação dominante e que, segundo Paulo Freire (1958), tem promovido o 'silêncio dessas minorias, defendendo outro fazer educativo - educação popular - definido por uma educação com o homem, e não sobre o homem, ou simplesmente, para ele. Uma educação promotora de mudanças criadoras de outras e novas disposições mentais no humano, enquanto coloca-o na sua contextura sociocultural, em condição compreensiva de seu mundo mesmo (MELO NETO, 2011, p. 32).

A educação popular, tendo em vista sua natureza e perspectiva epistemológica, está mais diretamente voltada às classes populares, tomando quase em sua totalidade a 
perspectiva freireana de educação como ato político ${ }^{3}$ e libertador, que objetiva a construção de uma sociedade mais justa e humana. Destaca-se, principalmente, por vislumbrar os princípios de dialogicidade presentes em Freire, grande defensor da educação contextualizada na interação entre educadores e educandos, visto que no diálogo encontrase o verdadeiro caminho para o conhecimento.

A educação popular revela, em suas manifestações iniciais, um contexto histórico de dominação ideológica por parte das classes dominantes, desencadeada pela evidente necessidade que os detentores do poder econômico sentiam de estabelecer a predominância de suas ideias em todos os setores da sociedade. Por se constituir num importante instrumento de controle social, a educação não poderia à margem desse propósito. Sobre esse cenário Beisiegel (1982) afirma:

Em todos os exemplos encontrados, era uma educação concebida e justificada pelas elites intelectuais como necessária à preparação da coletividade para a realização de fins determinados [itálicos do autor]. Assim entendida, esta educação para o "povo" explicava claramente as suas origens ideológicas e suas funções de "controle social" [grifos do autor], ou, em outras palavras, suas dimensões políticas, no sentido mais amplo do conceito (BEISIEGEL, 1982, p. 7).

A teoria do capital humano compreende a educação como uma mercadoria, visando uma competitividade geral entre pessoas, instituições, países, empresas, etc. Dessa forma, tenta investir a todo custo num cenário de educação competitiva e destinada à minoria, com objetivo de selecionar aqueles que melhor corresponderem aos seus interesses.

Por sua vez, a educação popular deve posicionar-se em oposição a essa conjuntura, buscando o enfrentamento dessas questões, a fim de não se deixar vencer pela hegemonia do capital, mas ao contrário, erguer sua bandeira de luta em favor da classe marginalizada, possibilitando um ensino que liberte e conscientize.

A EDUCAÇÃO DO CAMPO: BREVE REFLEXÃO SOBRE SUJEITOS, MOVIMENTOS SOCIAIS, PROGRAMAS E AÇÕES

\footnotetext{
3 Paulo Freire (1972) defende que todo ato educativo é um ato político, num processo dinâmico de transformação da realidade e das relações dos sujeitos, tanto de forma democrática como de forma imposta. Portanto, na perspectiva freireana, a educação não se distingue do ato político.
} 
Pensar o contexto do campo implica pensar em seus sujeitos (assentados, camponeses, quilombolas, indígenas, dentre outros) que muitas vezes são considerados minorias enquanto classe social, em sua trajetória de luta e formação humana. O campo precisa ser entendido como espaço de vida, cujos sujeitos possuem suas práticas, realizam suas ações, manifestam-se culturalmente e expressam seus valores, por isso, é importante respeitar esse território e a identidade da população campesina, bem como seu espaço de luta e resistência.

Os sujeitos e o campo possuem um forte vínculo, seja ele voltado ao patrimônio material ou ao imaterial, como também a laços sanguíneos ou às relações sociais estabelecidas. Apesar de ser uma população em minoria, se comparada ao contexto que envolve a cidade, Wortmann e Wortmann (1997, p.25) consideram que "o espaço camponês encolhe significativamente, mas as soltas continuam a povoar a memória, como condição de ser liberto".

Nesse contexto, cabe ressaltar a importância que os movimentos sociais ligados ao campo advogam para resguardar as expressões dos sujeitos políticos, tendo em vista a essência protagonista que é atribuída aos mesmos. Para o contexto camponês os movimentos sociais populares do campo construíram uma história marcada principalmente pela luta por terra, que por sua vez, caracteriza-se como luta de classe, afinal, como assinala Ribeiro (2010), os movimentos sociais populares expressam ação ou reação: ação de transformação ou reação de defesa. O foco é social, portanto, a educação também se insere nessa luta.

A mudança na passagem do modo de produção agrícola para a produção industrial demandou uma série de adaptações do meio rural, a fim de atender à realidade imposta pela indústria no meio urbano. Esse fato gerou uma crise no contexto rural, pois a economia passa a ser transformada e a agricultura vai perdendo seu espaço, apesar de ainda permanecer e sobreviver. Oliveira e Santos (2008) retratam um modelo de reterritorialização do solo brasileiro, a partir de uma perspectiva de produtividade do trabalho no campo, considerando que a reforma agrária não é mais reconhecida como um modelo de desenvolvimento no país, fato esse gerado pela força do capitalismo e consequentemente do agronegócio. 
Assim, os sujeitos do campo, mais especificamente aqueles que vivem do trabalho da terra (trabalhadores do campo ou rurais, por exemplo), precisaram não somente se adaptar, mas também se articular ao modo capitalista, ora através de uma interdependência de suas produções agrícolas, ora se submetendo a um novo tipo de trabalho em outro espaço, desencadeando o êxodo rural. O capitalismo começa, portanto, a marcar presença no campo através de empresas voltadas à produção e comercialização de produtos agrícolas, gerando um contexto heterogêneo de relação social e econômica na realidade rural, assim como referencia Santos (2016):

A implantação do paradigma do agronegócio no campo brasileiro representou a exploração e/ou expropriação de muitos trabalhadores que não puderam mais retirar as suas condições de existência no campo. Esse modelo econômico ampliou e reconfigurou a capacidade de extração de mais-valia e de aumento nas margens de lucro da burguesia que atua/ na agroindústria, sendo mediada pelo aparato jurídico, político, econômico e ideológico de controle do grande capital sobre a terra e a força de trabalho, depreendendo dessas relações de produção entre capital e trabalho um aumento significativo de excluídos no país. (SANTOS, 2016, p. 63)

Ainda diante dessa relação, Ribeiro (2010) retrata os desafios enfrentados pelos movimentos sociais na América Latina e na realidade brasileira, sinalizando que no contexto do campesinato a organização dos trabalhadores no país sofreu influência histórica das origens africanas, indígenas e também dos brancos europeus. Dentre os interesses que movem as classes na luta pela terra, destacam-se os grandes proprietários e os empresários de visão burguesa como integrantes desse cenário; em contrapartida, há também aqueles que lutam por reformas que sejam significativas e estruturantes.

Observa-se a importância do movimento camponês e do campesinato enquanto movimento social, tendo em vista serem sujeitos políticos que desenvolvem suas ações em torno da coletividade e transformação social. Sendo assim, tem-se um movimento pautado na emancipação, afinal, campesinato é totalidade, liberdade e autonomia, caracterizando-se como de extrema importância para a construção da cidadania a partir do desenvolvimento de uma sociedade justa.

A educação do campo não pode ser compreendida apenas como uma continuidade da educação rural, já que esta tem por objetivo principal oferecer um ensino à população rural, independente da forma a ser desenvolvida. Vale ressaltar que a educação rural surge 
inicialmente na década de 80 como ação da pasta criada pelo governo da Agricultura, Comércio e Indústria.

Ribeiro (2012) aponta para uma reflexão acerca do contexto das relações construídas socialmente pelo sistema de produção capitalista na educação, afirmando que devido à sua inserção nesse cenário, a escola, tanto urbana quanto rural, tem suas finalidades, programas, conteúdos e métodos definidos pelo setor industrial, pelas demandas de formação para o trabalho neste setor, bem como pelas linguagens e costumes a ele ligados (RIBEIRO, 2012, p 294). Recorrendo ao pensamento do autor, observa-se que, além de assumir o papel de retificadora, a trajetória da educação rural tem sido compreendida como instrumento do capital, já que nunca foi prioridade enquanto política pública, afinal, mesmo quando começa a ser pensada no país, teve como objetivo atender a demanda do sistema capitalista, preparando o camponês para o trabalho.

Caldart (2004) deixa claro que educação do campo pode ser compreendida enquanto categoria, no entanto, fixar um conceito não deve ser o maior objetivo. É preciso identificar questões que são importantes para a compreensão do que vem a ser a sua essência, observando a diferença que a disposição das palavras traz ao significado geral.

Conforme Caldart (2004, p. 149-150):

[...] é a luta do povo por políticas públicas que irão garantir o seu direito à educação e a uma educação que seja no e do campo. No: o povo tem direito a ser educado no lugar onde vive; Do: o povo tem direito a uma educação pensada desde o seu lugar e com a sua participação, vinculada à sua cultura e às suas necessidades humanas e sociais.

Na relação existente entre as experiências de trabalho e educação no contexto do campo, tem-se como exemplo a própria pedagogia da alternância, cujo contexto histórico está diretamente ligado às origens das Casas Familiares Rurais na França (CFRs) e da Escola de Família Agrícola (EFAs) na Itália. Sabe-se que há uma participação da Igreja e do Estado na Pedagogia da Alternância, no entanto, vale ressaltar que enquanto a igreja católica demonstrava grande preocupação com as questões sociais, era evidente o desinteresse do Estado pela escolarização dos camponeses, assim como corrobora Begnami (2004): [...] na maioria dos casos, a iniciativa se deu por meio da pastoral social das igrejas, sobretudo das Comunidades Eclesiais de Base - CEBs, ligadas à Igreja católica. (Begnami, 2004, p. 08) 
As experiências em pedagogia da alternância no Brasil evidenciam a proximidade com sindicatos e federação de trabalhadores rurais. Ribeiro (2010) aborda o desenvolvimento da pedagogia em Tempo-Escola e Tempo-Comunidade pela Fundação de Desenvolvimento, Educação e Pesquisa da Região do Celeiro (FUNDEP) e pelo Instituto de Capacitação e Pesquisa da Reforma Agrária (ITERRA), ambos associados à Via Campesina do Brasil $^{4}$, cuja alternância possui dimensão própria (num trabalho voltado para uma pedagogia social, a partir de movimentos sociais populares).

Para a autora, há contradições presentes em todo esse contexto de educação e trabalho, principalmente diante da relação "educação rural/do campo e trabalho agrícola", visto que a forma como os movimentos sociais tem se apropriado da pedagogia da alternância muitas vezes vem gerando divergências em seu desenvolvimento.

Outro fator importante a ser analisado consiste na criação do Programa Nacional de Educação na Reforma Agrária - PRONERA, como uma política educacional de abrangência nacional, sob responsabilidade direta do Ministério de Desenvolvimento Agrário, fundamentado na Lei n 11.947/2009, tendo o INCRA como principal executor de suas ações. Para Dos Santos e Souza (2012), o PRONERA caracteriza-se como importante política pública do campo que possui como principais metas: redução das taxas do analfabetismo, elevação do nível de escolarização nos assentamentos de reforma agrária, habilitação de professores, produção de materiais didático-pedagógicos, e reconhece os movimentos sociais como protagonistas dessa política.

O PRONERA atuou de maneira significativa e abrangente no contexto sócio-políticoeducacional dos sujeitos envolvidos na reforma agrária, não só através do acesso à escolarização para os assentados, mas também por ser um programa que busca desenvolver-se como política pública de referência para a educação do campo, a partir do fortalecimento das parcerias com os movimentos sociais.

\footnotetext{
${ }^{4}$ A respeito da Via Campesina, Desmarais (2002) define-a como sendo um movimento global autônomo, plural e desvinculado a filiações políticas e econômicas, composto por "organizações camponesas, pequenos e médios agricultores, mulheres rurais, trabalhadores rurais e comunidades agrárias indígenas na Ásia, as Américas, Europa Ocidental e Europa Oriental. África está em processo de integração. (DESMARAIS, 2002, p.94)". A FETRAP e o ITERRA estão vinculados à Via Campesina do Brasil.
} 
Nesse cenário educacional, o PRONERA trabalha com alfabetização e escolarização de jovens e adultos, formação profissional, formação profissional integrada de nível médio, formação de educadores, dentre outros, todos com foco no campo. No que diz respeito aos cursos técnicos ofertados, pode-se dizer que, a partir dos diálogos, discussões e trabalhos realizados pelos movimentos sociais, tem-se no PRONERA a perspectiva de uma educação profissional do campo, ou seja, compreendendo a concepção política da formação profissional e o trabalho como princípio educativo.

Sobre uma proposta pedagógica para a educação do campo e sua efetivação no sistema de ensino, é importante analisar o pensamento que Ramos, Moreira e Santos (2005) apresentam acerca dessa questão:

Os princípios da Educação do Campo são como raízes de uma árvore, que
tiram a seiva da terra (conhecimentos), que nutrem a escola e fazem com
que ela tenha flores e frutos (a cara do lugar onde ela está inserida e dos
sujeitos sociais a quem se destina). São ponto de partida de ações
educativas, da organização escolar e curricular e do papel da escola dentro
do campo brasileiro (RAMOS, MOREIRA e SANTOS, 2005, p. 37).

Observa-se a necessidade de se estabelecer uma relação de identidade em todo esse processo. Não basta somente a existência e execução de programas ou projetos direcionados ao campo e a uma educação do campo, é fundamental que a organização escolar esteja formada e constituída a partir de um comprometimento com o contexto do campo, bem como suas raízes e frutos, tornando-se, assim, uma educação para a vida.

A Educação do Campo precisa ser compreendida a partir dessa contextualização histórica apresentada, possibilitando a identificação dessa articulação com os sujeitos envolvidos em seus processos de luta. Nesse sentido observa-se sua relação com o contexto da Educação Popular, pois a luta dos movimentos sociais consiste na organização total dessa educação, a fim de que a mesma contemple uma formação completa e não aligeirada. Como as ações do e no campo giram em torno da terra, o projeto de uma escola com foco nessa essência deve ser construído tendo como base as lutas populares pela própria terra, pois sua concretização só se efetiva com a reforma agrária.

A Educação do Campo, em sua articulação com a Educação Popular, apresenta um projeto de educação emancipatória. Seus princípios relacionam-se às ações pautadas na coletividade e na manifestação dos movimentos sociais (populares e do campo), marcados por períodos de lutas e resistências em busca de um projeto educacional verdadeiramente 
associado à realidade inserida e considerando os sujeitos em seu meio social, a fim de promover uma educação de qualidade, contextualizada e libertadora.

EDUCAÇÃO DE JOVENS E ADULTOS (EJA): LEGISLAÇÃO, CARACTERÍSTICAS E ENTRELAÇAMENTO COM A EDUCAÇÃO POPULAR

É preciso considerar que a legislação e a história apontam para o fato de que a identidade da Educação de Jovens e Adultos vem sendo construída e modificada ao longo do tempo. A EJA representa um avanço no que diz respeito ao processo de inclusão desse público, no entanto, ainda se reproduz como política compensatória, e esse fato infelizmente desconsidera a trajetória de jovens e adultos.

Desde a colonização do Brasil pode-se afirmar que há uma trajetória histórica de uma educação voltada para jovens e adultos, pois o trabalho dos jesuítas era destinado à catequização/alfabetização dos povos indígenas, e nesse contexto estavam inseridos tanto crianças, quantos jovens e adultos, afinal, os padres tinham a missão de disseminar a fé e religião católica de forma ampla.

A permanência dos jesuítas no Brasil chegou ao fim com a chegada da família real, fato que desencadeou a expulsão dos mesmos do país. Portanto, diante desse contexto histórico-educacional, o processo educativo ganhou outro olhar e assumiu novas proporções, consequentemente a educação de adultos deixou de ser interesse do império.

A primeira Constituição de 1824, mesmo normatizando um ensino primário gratuito para todos, não contemplava as classes baixas, já que essas não tinham acesso à escola. Vale ressaltar que a legislação educacional tem grande importância dentro dessa discussão, pois reflete um processo decisivo de efetivação de direitos, possibilitando que os primeiros passos fossem trilhados.

Em 1930 é criado o Plano Nacional de Educação, que concebia a obrigatoriedade do ensino primário gratuito também às pessoas adultas, o que traz a Educação de Jovens e Adultos de volta ao olhar educacional. No que tange à legislação, este Plano pode ser caracterizado como um marco, pois a partir daí a EJA vai ganhando espaço e tendo seu contexto educacional desenvolvido ao longo de um percurso histórico marcado por vários processos distintos (criação do ensino supletivo, destinação de recursos, Campanha de erradicação do analfabetismo, movimentos sociais, Movimento Educação de Base, o 
Movimento Brasileiro de Alfabetização-Mobral, Fundação EDUCAR), afinal, muitos foram os caminhos trilhados a fim de chegar ao que se tem hoje.

Por sua vez, a Constituição de 1988 caracteriza-se como um avanço no sentido normativo, pois prevê o direito à educação para todas as pessoas, trazendo princípios importantes para a educação (como por exemplo: o pleno desenvolvimento da pessoa; preparo para o exercício da cidadania; qualificação para o trabalho) e amplia o dever do estado com a EJA, assim como pode ser observado em Oliveira (2007):

O inciso I do artigo 208 indica que o Ensino Fundamental passa a ser obrigatório e gratuito, "assegurada, inclusive, sua oferta gratuita para todos os que a ele não tiveram acesso na idade própria". Em seu artigo 214, a Carta Magna indica também a que legislação "estabelecerá o Plano Nacional de Educação, de duração plurianual, visando à articulação e ao desenvolvimento do ensino em seus diversos níveis e à integração das ações do poder público que conduzam à I - erradicação do analfabetismo, II - universalização do atendimento escola (OLIVEIRA, 2007, p. 4).

A partir daí, e mais especificamente na década de 1990, observou-se a participação de outros espaços sociais que também se dispuseram na luta pelo desenvolvimento da EJA, como as Organizações Não Governamentais-ONG's, grupos populares e universidades, além dos próprios municípios, os quais foram chamados pelo governo para se envolverem nesse processo de forma comprometida.

Levando em consideração um recorte temporal, tendo em vista o fato de que este trabalho não possui um caráter historicista, pode-se afirmar que através da LDB $\mathrm{n}$ 은 9394/1996, a EJA passa a ser tratada como uma modalidade:

O termo Educação de Jovens e Adultos substituiu a expressão Ensino Supletivo. Desde que passou a ter dois artigos específicos na Lei de Diretrizes e Bases no9394 de 1996 tornou-se uma modalidade de ensino e se destina ao sujeito que não teve acesso aos estudos ou dela fora excluída nos níveis Fundamentais e Médios, na faixa etária dos 07 aos 17 anos (ANDRADE, 2012, p. 213).

Além da marca deixada por essa legislação ao definir a EJA como modalidade de ensino, vale ressaltar que a LDB reforça a importância de se considerar as pessoas enquanto sujeitos sociais, com suas respectivas características e condições, as quais podem desencadear a ausência de uma escolarização na idade certa (fator que demarca e justifica essa modalidade na lei). Por conta da LDB, a EJA pode então ser reconhecida como política 
de Estado, sendo que este, por sua vez, passa a ter o dever de investir nessa modalidade. Vêse, portanto, que a LDB consolidou o Artigo 205 da Constituição de 1988, ao assumir a educação como um direito de todas as pessoas e compreendê-la como instrumento para exercício da cidadania.

Para além disso, pode-se dizer que a LDB foi um importante marco legal, que deu margem às discussões e reflexões sobre a educação enquanto direito. A partir dessas discussões por ela desencadeadas, tem-se no ano de 2000 a aprovação das Diretrizes Curriculares Nacionais para Educação de Jovens e Adultos (Parecer CNE/CEB 11/2000 e Resolução CNE/CEB 1/2000). Por meio delas o Conselho Nacional de Educação estabelece funções e bases legais da EJA, as quais serão analisadas e consideradas na organização do currículo (tanto em sua oferta quanto na estrutura dos componentes a serem trabalhados).

O princípio da igualdade deve ser o principal foco da Educação de Jovens e Adultos, pois como já foi discutido aqui, isso foi possibilitado pela Constituição de 1988 e mais posteriormente através da Lei de Diretrizes e Bases de 1996. Assim, a concepção de direito passa não apenas a fazer parte de um entendimento, mas começa a integrar-se no plano das ações.

Enquanto processo formativo, a Educação de Jovens e Adultos diferencia-se de uma escolarização, possuindo tempos distintos. Está relacionada à formação humana ao longo da vida, sendo uma aprendizagem que acontece em diferentes momentos e contextos, desde a fase infantil até a velhice. O processo de escolarização de jovens e adultos se insere dentro de toda a concepção de EJA, só não é possível resumir a isso o seu sentido ou função, porém, cabe a este trabalho destacar principalmente os enfoques dados ao contexto escolar e/ou institucional.

Como segmento de ensino, a EJA perpassa todos os níveis da Educação Básica no Brasil, tendo como público jovens, adultos e idosos que não tiveram acesso ou não deram continuidade aos seus estudos na idade regular. Divide-se em etapas que abrangem os níveis fundamental (entre o 1ํ e o 9o ano, com idade mínima de 15 anos) e médio (idade mínima de 18 anos), cujas disciplinas devem estar voltadas ao que define a Base Nacional Comum.

Assim, para fins de garantir esse direito constitucional da EJA, a escola pública constitui-se no principal instrumento para o exercício do mesmo, a partir de uma oferta de educação para todos (crianças, jovens, adultos, idosos), em todas as idades, possibilitando 
que a formação escolar aconteça sem exclusão. A efetivação dessa proposta só é possível quando há investimentos, pois sem recursos não há condições de realizar uma educação de qualidade inclusiva, assim como afirma Aguiar (2001, p 97): "não investir na Educação de Adultos é manter a exclusão, é desrespeitar o direito individual de acesso a um bem cultural essencial".

A EJA caracteriza-se com funções "reparadora, equalizadora e qualificadora", atribuídas pelo Parecer CNE/CEB 11/2000, sendo assim, ao reparar busca restaurar/devolver um direito que foi anteriormente negado, ao equalizar pretende oportunizar o acesso à educação e consequentemente ao mundo, por sua vez, a função qualificadora propicia a apreensão de conhecimentos ao longo da vida. Sobre isso, Cury (2005) pontua que:

[...] A Educação de Jovens e Adultos (EJA) representa uma dívida social não reparada para com os que não tiveram acesso à, nem domínio da leitura e escrita como bens sociais, na escola ou fora dela [...] Desse modo, a função reparadora da EJA, no limite, significa não só a entrada no circuito dos direitos civis pela restauração de um direito negado: o direito a uma escola de qualidade, mas também o reconhecimento daquela igualdade ontológica de todo e qualquer ser humano (CURY, 2005, p. 231).

Vale destacar que a luta por igualdade surge através dos movimentos sociais e civis, que também buscavam o direito pela educação para todos, com objetivo de alcançar de forma crítica uma transformação social. Portanto, as políticas públicas não surgem como presentes, mas sim como resultado de muitas ações, de grandes e valiosas conquistas.

Contextualmente falando, a EJA foi construída no seio dos diversos movimentos sociais, fazendo relação direta com a educação popular e com a educação de base. Assim, a EJA não existe somente pelo fato de ser contemplada nos amparos legais, mas principalmente porque possui sua identidade de luta e expressão, afinal, assim como diz Rummert (2007, p.38), "a educação de jovens e adultos, regulamentada como modalidade de ensino, é, sem dúvida, uma educação de classe".

Uma das marcas mais fortes da Educação Popular é ter como princípio básico a igualdade plena do ser humano, buscando, através da democratização do ensino, uma forma de trabalhar com a inclusão das pessoas na sociedade, numa luta constante não só pelo acesso e permanência, mas principalmente pela emancipação humana. 
Na sua essência a educação popular tenta seguir um caminho oposto à lógica de educação concebida pelo mercado. Não corrobora com a ideia de "educação para a formação de trabalhadores", cuja pretensão maior é torná-los aptos a ocuparem as vagas de emprego. O processo educativo está acima disso, pois caracteriza-se pela construção significativa do conhecimento, a partir da valorização e apropriação dos saberes existentes.

A reflexão acerca da Educação Popular e da Educação de Jovens e Adultos-EJA traz consigo impressões de proximidade em seus aspectos constitutivos, como por exemplo, a compreensão do seu público, a formação de militância na trajetória de luta, além da presença e atuação de movimentos sociais. Esses pontos são importantes e devem ser considerados, afinal, essa manifestação é decorrente do fato de que a EJA surge da Educação Popular. Antes de ser constituído formalmente enquanto modalidade, o ensino para adultos era realizado a partir de iniciativas e ações dos sujeitos, ou seja, da própria Educação Popular.

Há de se afirmar que o processo de exclusão social, bem como o percurso histórico percorrido, são fatores marcantes no contexto da Educação Popular e da EJA, portanto os mesmos possibilitam um entrelaçamento nessas ações, reafirmando principalmente o papel político e pedagógico que cada uma desempenha.

A Educação de Jovens e Adultos é um importante espaço de educação popular, representando um ambiente de escolarização para o jovem ou adulto que não tiveram oportunidades ou condições de frequentarem o ensino escolar no momento certo. No entanto, enquanto interface da educação popular, a EJA deve avançar em sua significação e aplicabilidade, possibilitando não apenas o acesso a uma certificação, mas contribuindo para a emancipação do ser, através da igualdade de direitos. Sobre isso, Vale (2001) comenta:

A nosso ver, essa relação dialética do homem com a realidade é que vai possibilitar a gestação de uma educação que, em sendo transitória, busca incessantemente um novo saber, uma nova qualidade de aprender, fundamentada na criticidade, na problematização, no questionamento, condições essenciais a uma ação educativa transformadora (VALE, 2001, p.71).

A EJA deve promover a formação humana em todos os seus aspectos. A partir do momento em que ela é percebida através de uma interface da Educação Popular, é possível lançar o olhar crítico para os sujeitos envolvidos no processo educativo, dispondo-se a 
conhecer e analisar a realidade popular, intercalando a essência da prática pedagógica com todo o processo político-histórico-cultural dos educandos.

\section{CONSIDERAÇÕES FINAIS}

Ao discorrer sobre Educação do Campo e Educação de Jovens e Adultos, este artigo buscou analisar a relação que esses contextos estabelecem diante do cenário da Educação Popular, levando em consideração a manifestação dessa realidade na construção da identidade de uma educação para todos.

As discussões evidenciaram que os interesses capitalistas interferem diretamente na sociabilidade humana, impondo modos de existência e sobrevivência que muitas vezes descontroem a pessoalidade e as características peculiares a um determinado contexto social ou regional. Configuram-se, também, num processo de negação ou privação de direitos, gerando, por sua vez, situações de exclusão e marginalização social.

Esse contexto é observado em vários aspectos da vida humana. No que diz respeito à educação, foco deste trabalho, percebe-se um processo de exclusão do próprio desenvolvimento educativo. Exemplo disso é a situação de distanciamento em que muitas pessoas se encontram, principalmente ao levar em consideração jovens e adultos, público característico de um silenciamento/esquecimento histórico.

A educação e a escola em si posicionam-se de forma errônea quando não atendem à demanda de toda a sociedade, o que remete à ideia de educação bancária discutida por Freire, a qual deixa de lado o despertar da autonomia do educando. É necessário, portanto, uma proposta de educação conscientizadora, através da tomada das lutas de classes, pois isso afeta o modo de criação da sociedade, afinal, assim como afirma Lombardi (2005):

Sendo a escola uma instituição historicamente determinada, como uma construção humana que se articula ao processo de produção das condições materiais de sua existência, como uma dimensão da realidade humana, para além da mera reprodução da sociedade burguesa, pode a educação articular-se plenamente na construção da sociedade sem classes. [...] Neste sentido, o educador precisa romper com as pedagogias escolares articuladoras dos interesses da burguesia e vincular sua concepção e sua prática a uma perspectiva revolucionária de homem e de mundo. Não se trata simplesmente de aderir a uma concepção científica de mundo e seu poder desvelador da realidade, mas de assumir, na teoria e na prática, isto é, na práxis, uma concepção transformadora da vida, do homem e do mundo (LOMBARDI, 2005, pp. 33-34). 
Nessa conjuntura encontram-se as perspectivas da Educação do Campo e da Educação de Jovens e Adultos, buscando a construção contra-hegemônica de educação a partir de uma concepção mais abrangente, na tentativa de promover a inclusão das pessoas através da compreensão de educação enquanto formação humana e social. O protagonismo dos movimentos sociais é, sem dúvida, um grande aliado desse processo, contribuindo para que todas as pessoas (camponeses, jovens, adultos, etc.) vejam o cumprimento do direito a educação para todos.

Cabe ressaltar que é importante compreender as discussões até aqui realizadas, considerando-as como passos iniciais que foram trilhados em relação à temática, já que a mesma envolve dimensões amplas no contexto da educação sob a perspectiva de emancipação humana. Portanto, torna-se evidente a necessidade de uma construção significativa desse processo a fim de se garantir a transformação da realidade social.

\section{REFERÊNCIAS:}

AGUIAR, R. H. A. Educação de Jovens e Adultos, movimentos sociais e políticas públicas elementos para uma conversa. Aprendendo com Jovens e Adultos - NIEPE - UFRGS, $\mathrm{n}$ 은 1 , Ano 2, Dez/2001.

ANDRADE, M. C. Um olhar sobre a atuação do serviço social no cenário do PROEJA no Instituto Federal Fluminense. In: ARAÚJO, J. M. de D; VALDEZ, G. do R. B. (org.). PROEJA: refletindo o cotidiano, v.02. Campos dos Goytacazes: Editora Essentia, 2012, p.211-231.

BEISIEGEL, C. de R. Política e educação popular: a teoria e a prática de Paulo Freire no Brasil. São Paulo: Ática. 304p, 1982.

BEGNAMI, J. B. Uma geografia da Pedagogia da Alternância no Brasil. Brasília: UNEFAB, 2004, p. 03-20. (Série: Documentos Pedagógicos)

BRANDÃO, C. R. Educação Popular. São Paulo: Brasiliense, 1985.

BRASIL. Conselho Nacional de Educação. Parecer CNE/CEB no 11/2001 e Resolução CNE/CBE no 1/2000. Diretrizes Curriculares para a Educação de Jovens e Adultos. Brasília: MEC, maio 2000.

CALDART, R. S. Pedagogia do movimento sem terra. São Paulo: Expressão Popular, 2004.

CALDART, R. S. Sobre educação do campo. III Seminário do Programa Nacional de Educação na Reforma Agrária (PRONERA). Luziânia, Goiás, 2012. Disponível em Acesso em 19 de mar. 
de 2017.

CURY, C. R. J. (Rel.). Diretrizes Curriculares Nacionais para a Educação de Jovens e Adultos Parecer $n^{\circ}$ CEB/CNE 11/2000. In: Silva, M. L. (Ed.). Concurso Magistério: apostila completa. Santa Cruz do Sul: Instituto Padre Réus; UNISC - Universidade de Santa Cruz do Sul - Pró Reitoria de Extensão e Relações Comunitárias, 2005. 491 p.

DESMARAIS, A. A. La Vía Campesina: Globalização e o poder dos camponeses. Ano 10, n. 10, 2002.

FREIRE, P. Pedagogia do oprimido. São Paulo: Paz e Terra, 1972.

LOMBARDI, J. C. Educação, ensino e formação profissional em Marx e Engels. In: LOMBARDI, J. C.; SAVIANI, D. (orgs.). Marxismo e educação: debates contemporâneos. Campinas: Autores Associados, 2005. p. 01-38.

MELO NETO, J. F. de. et. al. Educação Popular e "Experiência". Contexto \& Educação, Unijutaí, ano 26, n.85, p. 31-50, jan./jun. 2011. Disponível em: https://www.revistas.unijui.edu.br/index.php/contextoeducacao/article/view/440. Acesso em: 10 jan. 2015.

OLIVEIRA, R. L. P. Educação de Jovens e Adultos: o direito à educação. In: Mesa Redonda: Direitos Educativos e a EJA no Brasil. 16o Congresso de Leitura do Brasil - COLE, X Seminário de Educação de Jovens e Adultos. Campinas: UNICAMP, 2007. Disponível em: http://alb.org.br/arquivomorto/edicoes_anteriores/anais16/prog_pdf/prog01_01.pdf. Acesso em: 25 mai. 2020.

VALE, A. M. do. Educação popular na escola pública - 3a ed. São Paulo: Cortez, 2001. (Coleção Questões de Nossa Época; V. 8).

DOS SANTOS, A. R.; SOUZA, G. dos Santos. Integração entre educação básica e educação profissional na perspectiva da educação do campo. Revista de Educação Técnica e Tecnológica em Ciências Agrícolas, [S.I.], v. 3, n. 5, out. 2012. ISSN 2236-3483. Disponível em:http://www.agrimensura.ufrri.br/SEER/index.php?journal=retta\&page=article\&op=view \&path\%5B\%5D=1053\&path\%5B\%5D=893. Acesso em: 20 mar. 2020.

RIBEIRO, M. Movimento camponês, trabalho e educação: liberdade, autonomia, emancipação princípios fins da formação humana. São Paulo: Expressão Popular, 2010.

RIBEIRO, M. Educação Rural. In: CALDART, R. S; PEREIRA, I. B.; ALENTEJANO, P.; FRIGOTO, G. (org.) Dicionário da Educação do Campo. 2. Ed. Rio de Janeiro, São Paulo: Expressão popular, 2012. p. 293-299.

SANTOS, A. R. dos. Aliança (neo) desenvolvimentista e decadência ideológica no campo: movimentos sociais e reforma agrária do consenso. Curitiba: CRV, 2016. 
SANTOS, C. A. dos. (org.). Por uma Educação do Campo: Campo -Políticas Públicas Educação. Brasília: Incra; MDA, 2008.

RAMOS, M. N.; MOREIRA, T. M.; SANTOS, C. A. Referências para uma política nacional de educação do campo: caderno de subsídios. Brasília: Secretaria de Educação Média e Tecnológica, Grupo Permanente de Trabalho de Educação do Campo, 2005.

RUMMERT, S. M. A educação de jovens e adultos trabalhadores brasileiros no século XXI. O "novo" que reitera antiga destituição de direitos. Revista de Ciências da Educação, no. 2. jan./abr., 2007.

WORTMANN, E. F. WORTMANN, K. O Trabalho da terra: a lógica e a simbólica da lavoura camponesa. Brasília: Ed. Universidade de Brasília.

Recebido em 22 de Abril de 2020.

Aprovado em 10 de maio de 2020

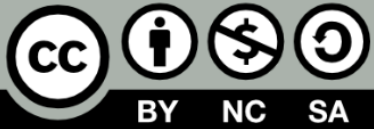

